\title{
A new approach for flood forecasting of river flows
}

\author{
M. Mohssen \\ Department of Environmental Management, \\ Lincoln University, New Zealand
}

\begin{abstract}
Flood warning mainly depends on reliable flood forecast models. Literature is rich in flood modelling techniques, but failures of these models, especially on the very short scale such as hourly flows, do often cause devastating impacts on the communities affected by these floods, and on many occasions result in loss of lives. This paper presents a new approach for flood forecasting of river flows based on the projection theorem in Hilbert space.

The new modelling process obtains the projection of hourly flow rates on hourly rainfalls over the catchment at previous hours to the projected flow rate. A total of 25 flow events observed for the Leith River in Dunedin, New Zealand, along with their corresponding observed rainfalls at two sites in the catchment have been identified and applied to calibrate and validate the derived model. The proposed modelling technique was capable of simulating the flow process for the Leith River, and is a promising tool for flood forecast when other models fail. The proposed model is easy to apply, doesn't imply a lot of assumptions or parameters, as other models usually require, and can be used for long term forecast based on forecasted hourly rain one day or more before the event, or real time forecast during the event itself based on rainfall which has been already gauged. However, for real time (short term) forecast, the forecast time can be a few hours based on the catchment area and its topography which can lead to a fast flow to the outlet.

Keywords: flood forecast, flood modelling, rainfall-runoff, projection in Hilbert Space.
\end{abstract}




\section{Introduction}

Natural disasters cause devastating damages to all types of lives on earth, and their negative impacts can last for long periods with a huge cost to mitigate. Floods are the most common natural disasters, and unlike other forms of natural disasters which usually occur in specific regions such as earthquakes, volcanoes, hurricanes, or tornadoes, floods occur almost everywhere, and no community is immune from their devastating damages. Flood warning can be quite effective in mitigating the impacts of a coming event, simply by getting prepared. Even with the existence of flood protection schemes, there is usually the potential for a bigger flooding event than what the scheme was designed for. The Environment Agency of UK and the strategic plan for the US National Weather Service indicated the urgent need for major investment to develop new forecast models for flood warning $[1,2]$.

Flood forecasting is the corner stone for an efficient flood warning system. New technology and the use of satellite and radar data have significantly improved our capability of forecasting rainfall, even on an hourly basis, for short term periods such as the next few hours or longer forecast such as the next 24/48 hours. However, due to the complexity of this natural event, and the high spatial and temporal variability of rain, the main driving force for flooding, in addition to the complex hydrological aspects and characteristics of the catchment area, it is usually hard to accurately forecast the coming flood event [1]. Many of the available forecast models in the literature, especially those based on watershed modelling and hydraulic/hydrologic routing, require a lot of data and include a lot of assumptions for solving the concerned equations, which adds to their complexity and applicability. There are many reports in the media and anger in the communities over failure of their governments/authorities to provide proper flood warning [3-7].

Time series analysis and modelling, such as ARIMA models, have been applied in the literature for simulating streamflows. However, these models work more for longer time periods where stationarity conditions can be assumed, or achieved by removing apparent cycles or trends [8]. For hourly flows during a significant event, the series is quite non-stationary, and flow rates react directly and are highly related to the rainfall intensity during the period preceding this flow. ANN has been recently applied for flood forecasting, and several techniques have been suggested for their applications to hourly time steps $[9,10]$.

In New Zealand, floods are the most costly natural disaster. About 935 devastating floods occurred during the period 1920 to 1983 in New Zealand [11]. Dunedin is the second largest city in the South Island of New Zealand, with a population of about 120,000 (Statistics New Zealand, 2013). The Leith River, which drains about $45 \mathrm{~km}^{2}$ of mainly hilly areas around Dunedin, goes through the city and passes by the prestigious University of Otago. Most of the northern part of Dunedin lies within the flood plain for the Leith River. A big flooding event for the Leith River can cause significant damage and loss to Dunedin in particular, and the whole Otago Region in general. The Leith River has history of flooding, and Dunedin experienced extensive damage and inundation during the 1877, 1923 
and 1929 flood events. The Otago Regional Council has recently conducted studies for flood protection schemes for the Leith River, and has applied for consents to carry out the needed work.

\section{Flood modelling of the Leith River}

The Leith catchment has an area of about $45 \mathrm{~km}^{2}$, and extends on the north/north west of Dunedin, with Lindsay Creek joining the main Leith in the northern side of Dunedin. There are two sites for rainfall gauging, the first one is at Sullivans Dam near the northern boundary of the catchment, while the second site is in the northern Pinehill suburb of Dunedin. The flow site is located in the southern reach of the river, near the University of Otago. The Leith River, after passing the University of Otago, finds its way to the Otago harbour. Figure 1 shows the catchment area with the locations of rainfall and flow sites. The Leith River has an average flow of $0.694 \mathrm{~m}^{3} / \mathrm{s}$, while its "observed" maximum flow is $114 \mathrm{~m} / \mathrm{s}$, recorded on 18 February 1991.

\subsection{Model development and formulation}

The catchment area of the Leith River is not big, and this usually results in a significant component of the runoff contributing to its high flow hydrograph, compared to the base flow component which is usually very small (as shown in Fig. 2). Thus, the straight line approach for separating the base flow has been applied to estimate the runoff hydrograph due to the rainfall event over the catchment [12]. This approach should result in good estimates of the runoff hydrograph, as any error in estimating this very small base flow will not have effect on the much bigger runoff component. The runoff hydrograph is obtained by simply subtracting the estimated base flow from the flow hydrograph.

The basic concept of this model is based on the projection in Hilbert Space [8] of the hourly river flows on the span of hourly rainfall data preceding these flows.

This model represents an extension of the models developed by [13] and [14] for the univariate and multivariate flood forecast of lake levels.

Thus, the flow rate at time $t, Q_{t}$, is projected on the span of rainfalls at antecedent times: $R_{t-j}, j=L_{1}$ to $L_{2}$, where $L_{1}$ and $L_{2}$ represent lag-1 and Lag-2 hours before time t. Thus:

$$
\hat{Q}_{t}=\sum_{j=L 1}^{L 2} \alpha_{j} R_{t-j}
$$

For $\hat{Q}_{t}$ to have the minimum distance "difference" from $\mathrm{Q}_{\mathrm{t}}, \mathrm{Q}_{\mathrm{t}}-\hat{Q}_{t}$ should be orthogonal to all elements of the span of the vector $\mathbf{R}\left(\mathrm{R}_{\mathrm{t}-\mathrm{j}}, \mathrm{j}=\mathrm{L}_{1}\right.$ to $\left.\mathrm{L}_{2}\right)$. In Hilbert space, this yields the following equation:

$$
<\mathrm{Q}_{\mathrm{t}}-\widehat{Q}_{t}, \mathbf{R}>=0, \quad \text { where }<\mathrm{X}, \mathrm{Y}>=\mathrm{E}[\mathrm{XY}] \text { in Hilbert space }
$$

Thus,

$$
<\mathrm{Q}_{\mathrm{t}}-\sum_{j=L 1}^{L 2} \alpha_{j} R_{t-j}, \mathbf{R}>=0, \mathrm{j}=\mathrm{L}_{1}, \mathrm{~L}_{1}+1, \ldots, \mathrm{L}_{2}
$$




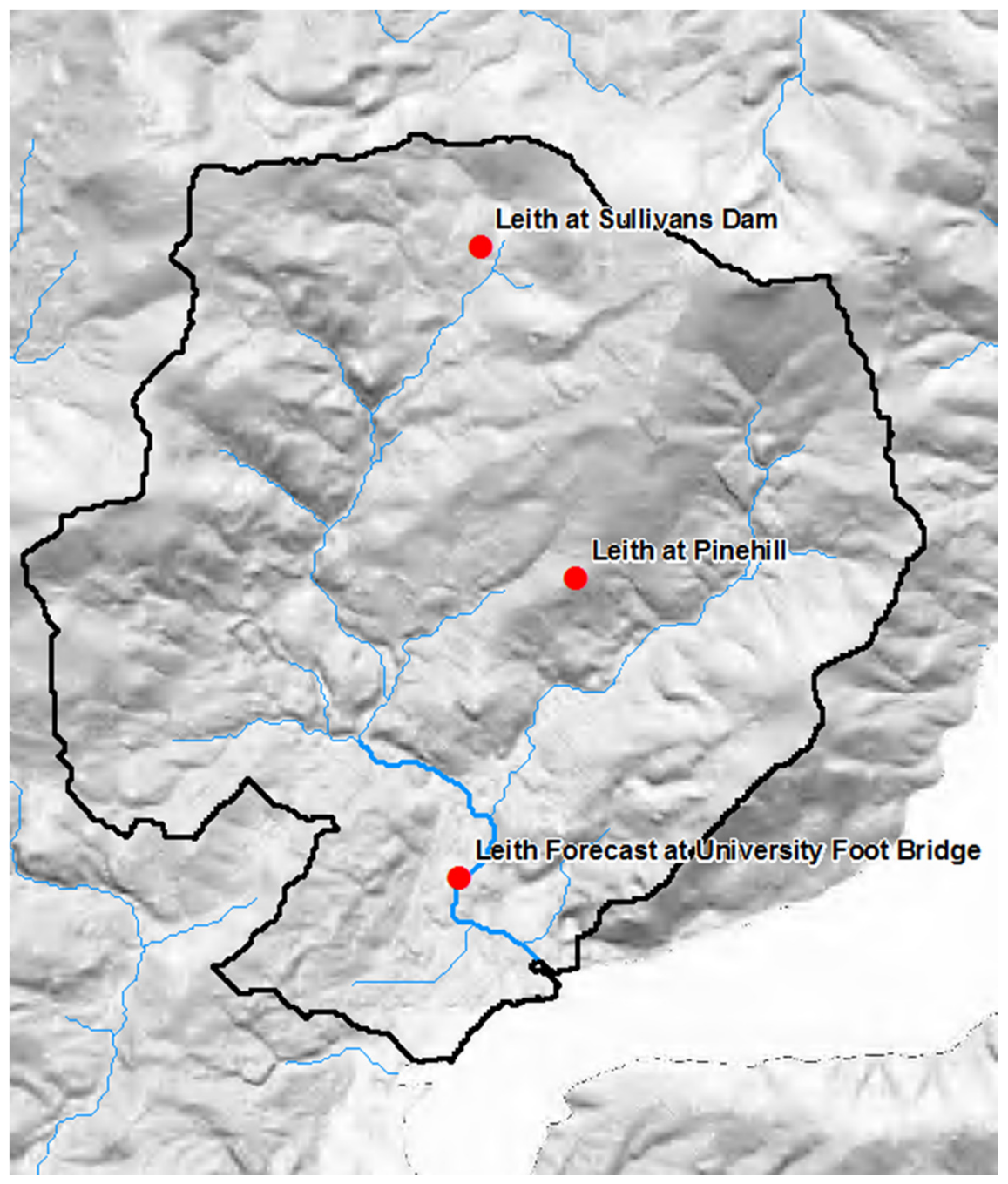

Figure 1: Locations of rainfall and flow sites in the Leith catchment.

Equation (3) produces a system of $\left(\mathrm{L}_{2}-\mathrm{L}_{1}+1\right)$ linear equations, which can be solved simultaneously to obtain the parameters $\alpha_{j}, \mathrm{j}=\mathrm{L}_{1}$ to $\mathrm{L}_{2}$. The projection theorem guarantees that the produced solution is the unique mapping of $\mathrm{Q}_{t}$ onto $\mathrm{R}$.

The projection theorem guarantees that the model provided by (3) will produce coefficients of $\left(\mathbf{R}_{\mathbf{t}-\mathbf{j}}\right)$ for the best forecasts of $\mathrm{Q}_{\mathrm{t}}$. It is assumed in this research that the relationship between $Q_{t}$ and $R_{t-j}$ is linear, which might not be the best choice. However, based on the model application which is shown later, this proved to be satisfactory. More research is recommended to consider alternative relationships. 


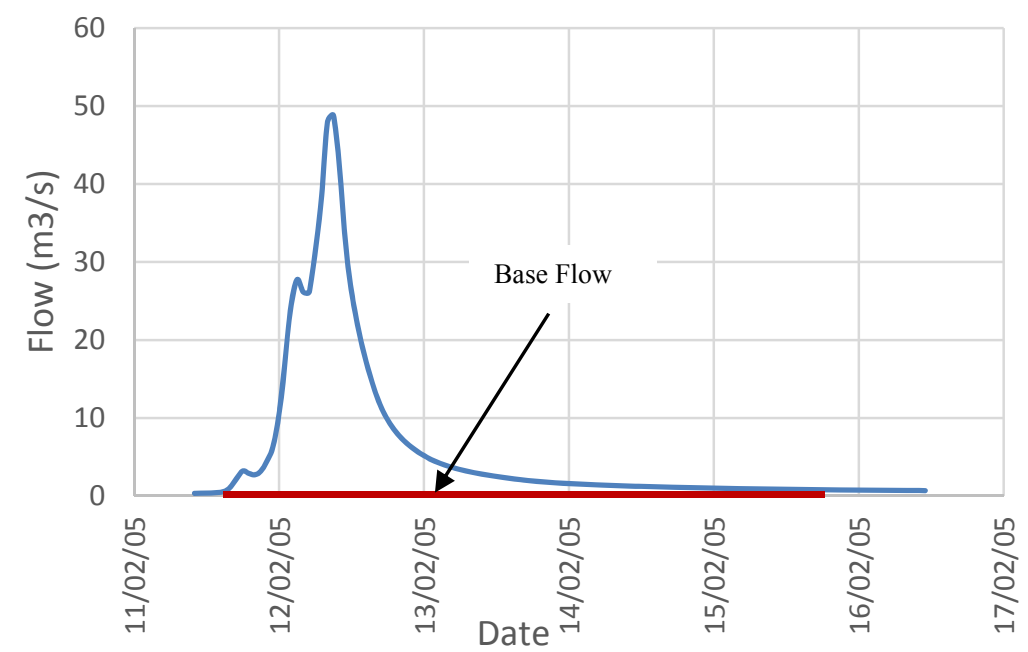

Figure 2: A high flow event for the Leith River showing the base flow.

\subsection{Model calibration}

A total of 25 high flow events have been selected from the available record during the period March 2000 until November 2013. Twenty three events have been used for model calibration and two events have been utilised to test the validation of the developed model. Rainfall over the whole catchment was estimated by applying Thiessen polygon method to calculate the weight for each rainfall site, and in turn obtain the average rainfall over the whole catchment area. Thus, one time series of average hourly rainfalls has been estimated and used in this case study. For the calibration process, hourly lagged rainfalls for all the events were joined together in one input file to the model so that the estimated parameters $\alpha_{j}, \mathrm{j}=\mathrm{L}_{1}$ to $\mathrm{L}_{2}$ are based on all the 23 events, and not only on one event. Figure 3 presents lagged correlations between runoff flow rates and observed rainfalls at lags 0 to 10 hours prior to the flow rate. The figure indicates that lags 3 and 4 are the highest, and it is a must to include these rainfalls for the flood forecast of the Leith River. If L1 equals 3 , then this will produce a 3 hours warning before this flow rate for a real time forecast during the rainfall event. However, if this forecast is based on rainfalls during the next day, the warning time would be much longer.

Figure 4 shows the observed versus the "forecasted" flows for the combined 23 events which were used in the calibration process.

In general, the model simulated "satisfactorily" the underlying hourly runoff process, but underestimated some of the significantly high events, and also overestimated others. However, it has to be stated that it is usually very hard for any model on an hourly basis to simulate accurately the underlying hydrologic process. Add to this, that this newly developed model does not "explicitly" 


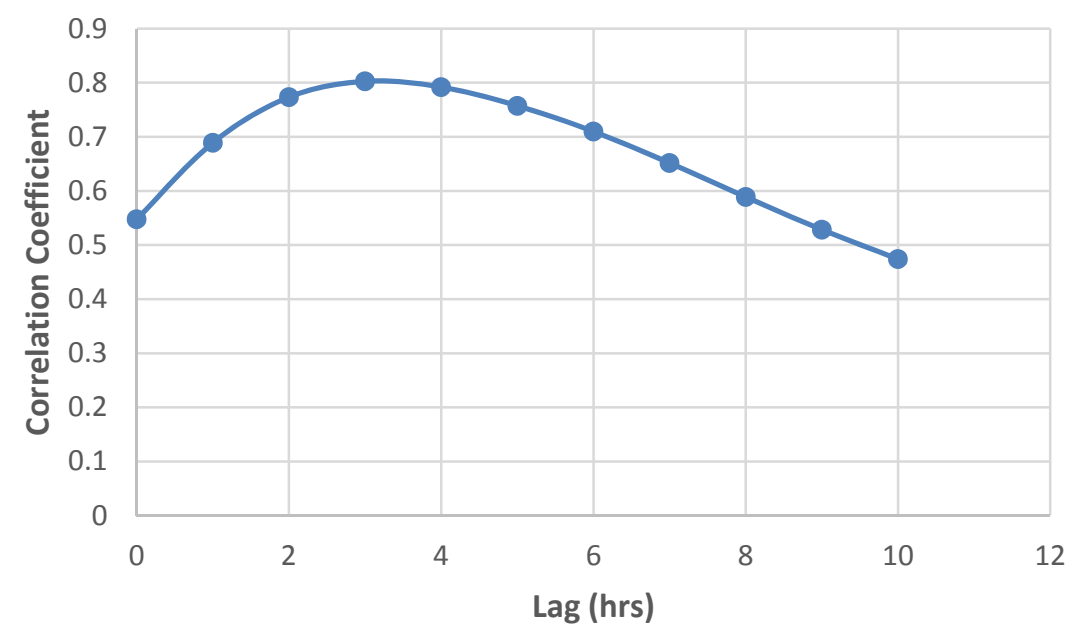

Figure 3: Lagged cross correlations between runoff flow rates and rainfalls.

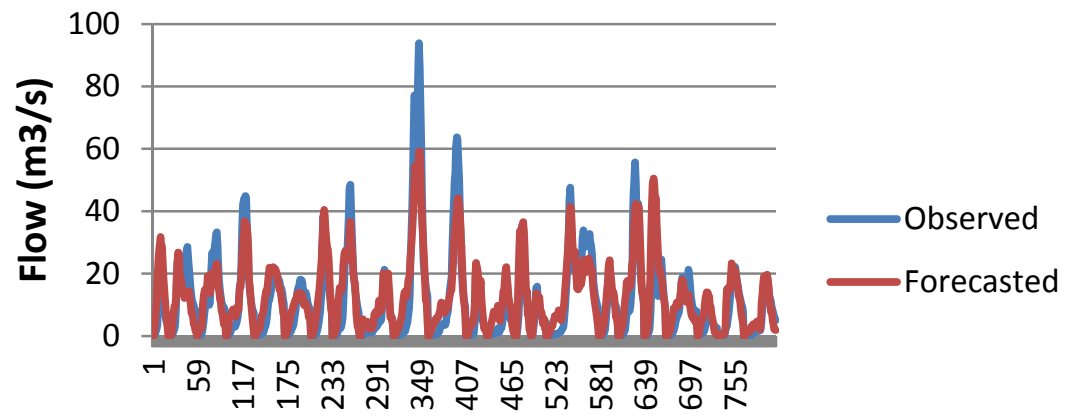

Time (hrs)

Figure 4: Results of the calibration process.

account for hydrologic abstractions, or losses from rainfall before it becomes runoff. However, this is imbedded in the estimated parameters to obtain the best match between the observed and the forecasted flows. Still, the model performed reasonably well. The overall value for Filliben correlation coefficient, which is a measure of how good are the forecasted flows compared to the observed ones, is 0.9 .

\section{Model testing}

Validation of the fitted model was carried out by applying the model to rainfall events which were not included in its calibration process. Thus, these estimated 
parameters are not "biased" toward these events. These two high flow events occurred during the periods 30 July to 1 August 2008 and 15 to 20 June 2013. Table 1 shows the forecasted peak flows versus the observed ones for the two events, while figures 5 and 6 show the simulation of the fitted model to forecast hourly flows for the two events. The table shows that the forecasted peak flows were within $12 \%$ to $23 \%$ of the observed peaks, with determination coefficients $\left(\mathrm{R}^{2}\right)$ and Filliben correlation coefficients (FC) higher than $90 \%$. It should be noted that each event has two peaks, and the model was capable of capturing this behaviour for the second event, but was not able to "properly" simulate the second

Table 1: $\quad$ Observed vs. forecasted Leith River peak flows.

\begin{tabular}{|l|l|l|l|l|l|l|}
\hline $\begin{array}{l}\text { Event } \\
\text { Date }\end{array}$ & Peak & Observed & Forecast & $\mathrm{R}^{2}$ & FC & $\begin{array}{l}\% \\
\text { Error }\end{array}$ \\
\hline $\begin{array}{l}\text { July } \\
2008\end{array}$ & 1 & 26.4 & 23.2 & & & -12.1 \\
\cline { 2 - 7 } & 2 & 28.4 & 21.9 & 0.97 & 0.98 & -22.9 \\
\hline \multirow{2}{*}{$\begin{array}{l}\text { June } \\
2013\end{array}$} & 1 & 49.2 & 37.8 & & & -23.2 \\
\cline { 2 - 7 } & 2 & 18.5 & 15.7 & 0.91 & 0.96 & -15.3 \\
\hline
\end{tabular}

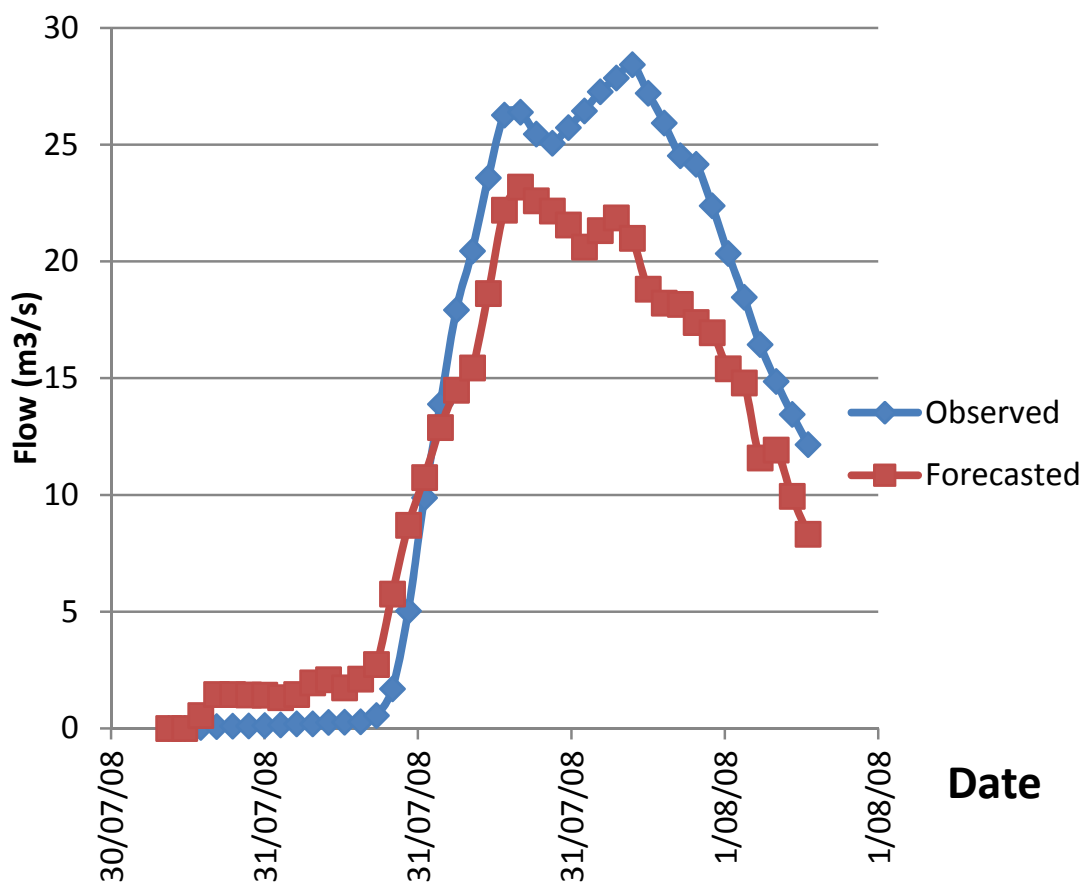

Figure 5: Observed vs. forecasted runoff hydrographs for the rainfall event July 2008. 


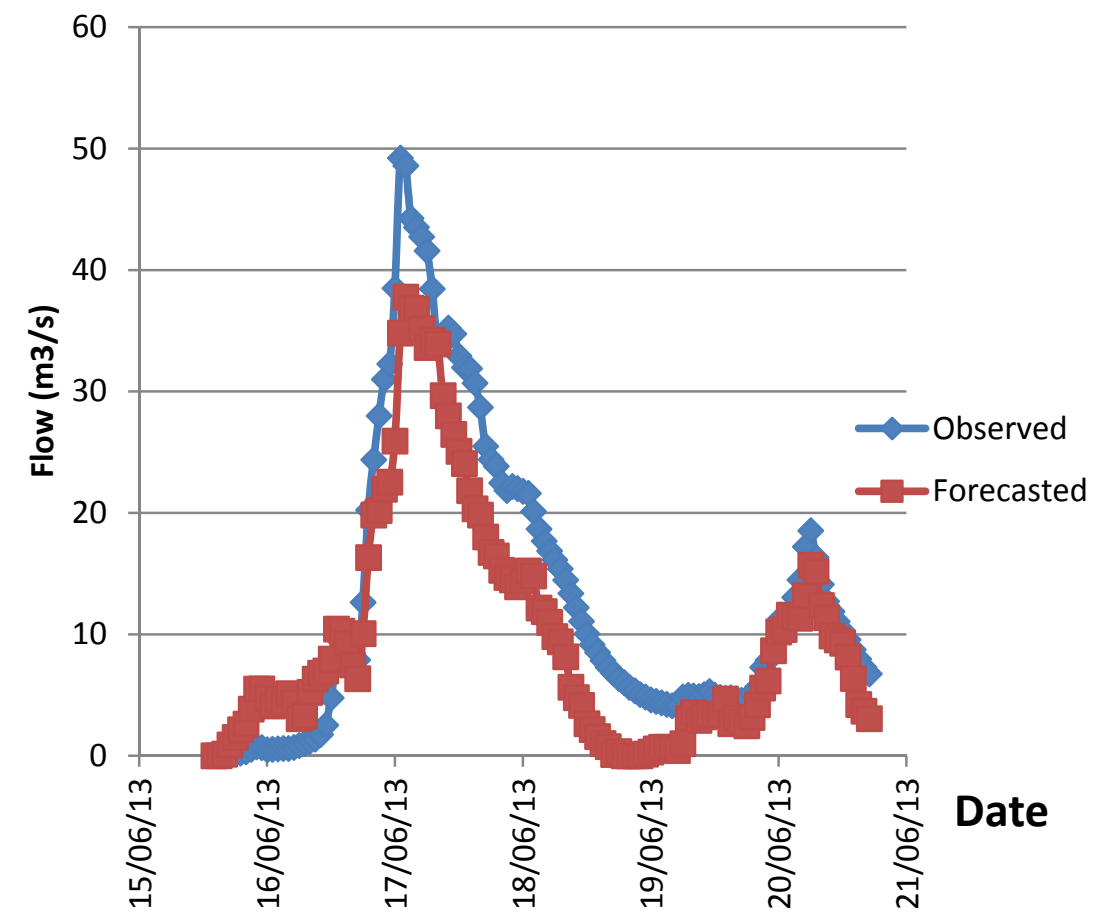

Figure 6: Observed vs. forecasted runoff hydrograph for the rainfall event June 2013.

peak of the first event. There is only one determination coefficient and one Filliben correlation coefficient for each event, as shown in the table. The figures confirm the conclusion that the model is capable of forecasting the Leith River high flows, and responded well to the rising limb and the recession of the two events.

\section{Conclusions}

A newly derived approach to forecast river flows based on the projection theorem in Hilbert space has been presented and applied for the Leith River in Dunedin, New Zealand. The model, once derived and calibrated, is easy to apply and can be used for forecasting during a rainfall event with a lead time of 3 hours, or can be used for a much longer time if forecasted rainfall is used. The model required only hourly rainfall and flow data for its calibration, and only hourly rainfall data for its application for flood forecast. Despite the fact that the model, in its current form, does not "explicitly" has a function to account for hydrologic abstractions from rainfall, still it produced satisfactorily results with its implicit inclusion of rainfall losses during the projection process. 


\section{References}

[1] Bye, P. \& M. Horner, Easter 1998 Floods Report by the Independent Review Team to the Board of the Environmental Agency, vol 1, Environmental Agency, Bristol, 1998.

[2] Demeritt D., H. Cloke, F. Pappenberger, J. Thielen, J. Bartholmes \& MariaHelena Ramoset, Ensemble predictions and perceptions of risk, uncertainty, and error in flood forecasting, Environmental Hazards, vol 7, pp. 115-127, 2007.

[3] McClure, M \& T. Howell, Forecast failure: how flood warning came too late for southern Albertans, Calgary Herald, December 31, 1991.

[4] Datta, S., CWC failed to forecast, alert about floods, DNA, New Delhi, June 26, 2013.

[5] Socialist Equality Party (Australia), Australia's floods: a failure of government and the profit system, WSWB World socialist web site, January 29, 2011.

[6] Daily Express newspaper, Anger over flood warning failure, Daily Express paper, London, July 9, 2012.

[7] Handmer, J., Are Flood Warnings Futile? Risk communication in emergencies, the Australian Journal of Disaster and Trauma Studies, $2000-2$.

[8] Brockwell, P. J. \& R. A. Davis., Time Series: Theory and Methods, Springer-Verlag New York Inc., pp. 46-51, 1991.

[9] Tiwari, M. K., Chatterjee, C., Development of an accurate and reliable hourly flood forecasting model using wavelet-bootstrap-ANN (WBANN) hybrid approach, J. of Hydrology 394, pp. 458-470, 2010.

[10] Chen-ShenHsien; Lin-YongHuang; Chang-LiChiu; Chang-FiJohn, The strategy of building a flood forecast model by neuro-fuzzy network. Journal of Hydrological Processes, 20(7), pp. 1525-1540, 2006.

[11] McSaveney, E., Floods - New Zealand's number one hazard, Te Ara - the Encyclopedia of New Zealand, updated 2-Mar-09.

[12] Chow, V.T., D. R. Maidment \& L.W. Mays, Applied Hydrology McGrawHill, 1988.

[13] Mohssen, M. and Goldsmith, M., Flood Forecasting of Lake Levels: A New Concept. Int. J. of Safety and Security Eng., 1(4), pp. 363-375, 2011.

[14] Mohssen, M., A Multivariate Model for Flood Forecasting of Lake Levels. Int. J. of Safety and Security Eng., 3(2), pp. 141-152, 2013. 